\title{
Trans-sialidase delivered as a naked DNA vaccine elicits an immunological response similar to a Trypanosoma cruzi infection
}

\author{
F. Costa ${ }^{1}$ \\ V.L. Pereira-Chioccola1,2, \\ M. Ribeirão ${ }^{1}$, \\ S. Schenkman ${ }^{1}$ and \\ M.M. Rodrigues ${ }^{1}$
}

\author{
${ }^{1}$ Departamento de Microbiologia, Imunologia e Parasitologia, \\ Escola Paulista de Medicina, Universidade Federal de São Paulo, São Paulo, SP, Brasil \\ ${ }^{2}$ Laboratório de Xenodiagnóstico, Instituto Dante Pazzanese de Cardiologia do Estado \\ de São Paulo, São Paulo, SP, Brasil
}

\begin{abstract}
Correspondence
M.M. Rodrigues

Departamento de Microbiologia,

Imunologia e Parasitologia

EPM, UNIFESP

Rua Botucatu, 862, 60 andar

04023-062 São Paulo, SP

Brasil

Fax: + 55-11-571-1095

Abstract

Trypanosoma cruzi, the protozoan parasite that causes Chagas' disease, does not synthesize sialic acid, but expresses a trans-sialidase (TS) that catalyzes the transfer of sialic acid from host glycoconjugates to the parasite surface. Here, we review studies that characterize the immune response to the catalytic domain of the enzyme in humans during Chagas' disease or in mice following immunization with the TS gene. In both cases, there are antibodies that strongly inhibit the enzymatic activity and generation of interferon- $\gamma$-producing $T$ cells.
\end{abstract}

E-mail: rodriguesm.dmip@epm.br

Presented at the International

Symposium "The Third Revolution on Vaccines: DNA Vaccines",

Belo Horizonte, MG, Brasil,

November 3-7, 1997.

Research supported by FAPESP, CNPq, Ministério da Ciência e Tecnologia-PADCT, and PRONEX.

Received September 15, 1998 Accepted November 10, 1998
Key words

- DNA vaccination

- Trans-sialidase

- Chagas' disease

\section{Chagas' disease}

Trypanosoma cruzi is a protozoan parasite and the causative agent of Chagas' disease. In spite of considerable efforts to eradicate the triatomine, the disease is still transmitted in several states of Brazil and other South American countries, endangering millions of people. Also, the existence of 10-14 million individuals in the chronic stages of the disease is a major threat for transmission through blood transfusion.

After contact with trypomastigotes of $T$. cruzi, mammalian hosts develop the acute phase of Chagas' disease, characterized by patent parasitemia that lasts for several weeks. The chronic phase initiates when the parasitemia declines significantly, becoming subclinical. Most individuals carry this infection for life. Drug treatment is prolonged and its efficacy is not high. In recently infected children, treatment is $55.8 \%$ efficient (1). The efficacy is even lower (19.1\%) in adults infected for many years (2). The poor prospect of treatment raises the possibility that immune interventions, such as immunization, could be an additional weapon to increase treatment efficacy in patients who do not respond to conventional chemotherapy.

\section{Structure of the trans-sialidase}

Several surface antigens of infective forms of $T$. cruzi (trypomastigotes and amastigotes) have been grouped into a super-family defined by the presence of consensus sequences homologous to bacterial sialidases (3-5). These surface antigens are a highly polymorphic family of proteins with molecular masses ranging from 85 to $200 \mathrm{kDa}$. Many of these 
Figure 1 - Schematic view of cruzi trypomastigotes and the recombinant protein based on the $\mathrm{N}$-terminal region. the trans-sialidase (TS) of T.

proteins have been implicated in a number of biological processes important for $T$. cruzi interaction with host cells and extra-cellular matrix proteins (6-11). One group of these proteins are enzymes denominated transsialidase (TS) that catalyze the transfer of sialic acid to ß-galactosyl residues of mucinlike glycoproteins that are present on the surface of $T$. cruzi trypomastigotes and epimastigotes $(12,13)$.

The importance of the acquisition of sialic acid is not completely known. However, there are suggestions that the transfer of sialic acid present on the surface of the host cell to the parasite may help trypomastigote adhesion and penetration into nonphagocytic cells $(9,14)$. Sialic acid also provides a strongly negatively charged cover that protects parasites against human lytic antibodies specific for $\alpha$-galactosyl residues which are abundant on the trypomastigote surface (Pereira-Chiccola VL, Acosta-Serrano A, Almeida I, Rodrigues MM, Travassos LR and Schenkman $\mathrm{S}$, unpublished results).

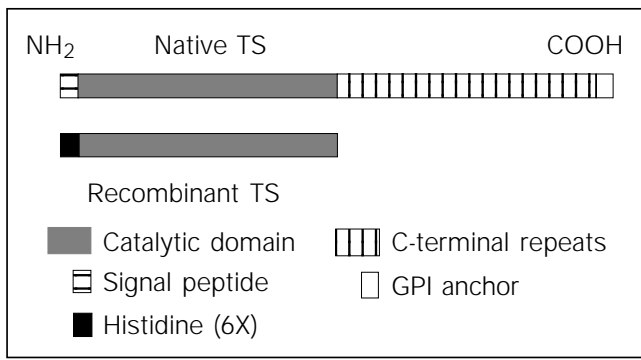

Figure 2 - Human antibody recognition of native and recombinant (Rec.) trans-sialidase (TS) by ELISA.

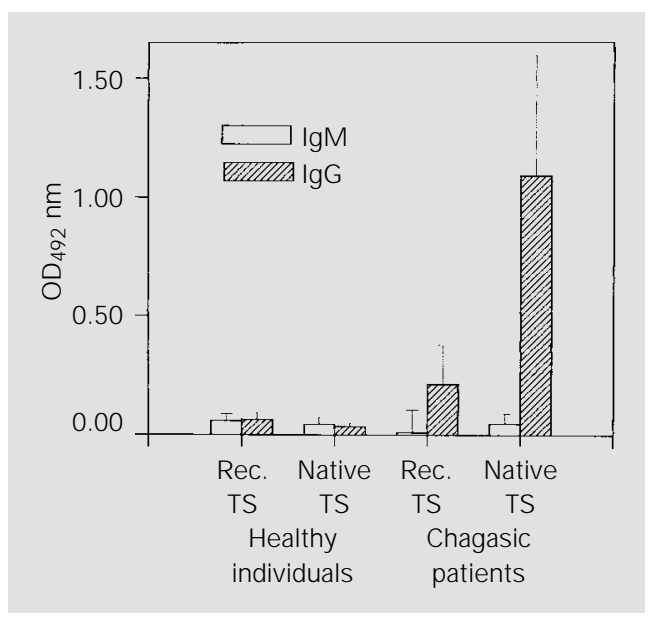

In trypomastigote forms found in the vertebrate host, TS is formed by multimeric aggregates with molecular mass $\geq 400 \mathrm{kDa}$ $(15,16)$, that upon denaturation migrates as multiple bands ranging from 160 to $220 \mathrm{kDa}$ in SDS-PAGE $(13,17)$. Trypomastigote TS has essentially 2 different domains. The $\mathrm{N}$ terminal region contains the catalytic domain of the enzyme (Ref. 18 and Figure 1). The C-terminal, or CTR, is composed of amino acid repetitions. TS is linked to the parasite membrane by a glycosyl-phosphatidylinositol (GPI) anchor and is continuously shed into the supernatant. Details concerning the TS gene and its protein structure have been described by Schenkman et al. (5).

\section{Immunogenic properties of TS during human infection with T. cruzi}

Serological studies have shown that TS is highly immunogenic during natural human infection with T. cruzi. Almost all individuals develop antibodies that recognize an epitope within the CTR of TS (3). Chagasic patients also generate antibodies specific for the $\mathrm{N}$ terminal region of TS that strongly inhibit its enzymatic activity $(19,20)$. Comparatively, chagasic antibodies preferentially recognize the native TS which contains the CTR rather than a recombinant TS which contains only the N-terminal catalytic domain (Figure 2). Nevertheless, there is direct evidence that inhibitory antibodies which recognize the catalytic domain of TS passively protect mice against bloodstream trypomastigote infection (21). These inhibitory antibodies differ from antibodies against the CTR that are unable to block enzymatic activity and were not reported as protective $(21,22)$.

To complement these serological studies, we used a recombinant protein based on the sequence of the $\mathrm{N}$-terminal catalytic domain to determine whether chagasic patients develop a cell-mediated immune response (CMI) to TS. CMI was measured by in vitro T-cell proliferation, and interferon- $\gamma$ and interleu- 
kin-4 production in response to the recombinant protein. We found that cells from $78 \%$ of the chagasic patients proliferated in response to the recombinant TS. Most relevant, cells from $88 \%$ of these patients produced interferon- $\gamma$ upon stimulation with the recombinant protein (Figure 3 and Ribeirão M, PereiraChiccola VL, Fragata-Filho A, Renia L, Schenkman S and Rodrigues MM, unpublished results). In contrast, interleukin-4 was not detected in response to TS. CMI was specific, because healthy individuals never exposed to $T$. cruzi infection failed to react with this recombinant protein. From these results, we concluded that the TS catalytic domain is recognized by $\mathrm{T}$ cells and antibodies in a large proportion of patients infected with $T$. cruzi.

\section{Immunogenic properties of TS delivered as naked DNA vaccine}

Based on the results that support the concept that TS is highly immunogenic during natural infection with $T$. cruzi, we determined whether immunization with plasmids containing the TS gene could elicit immunity against experimental Chagas' disease. Initially we compared the immunogenicity of several plasmid vectors containing a gene encoding the catalytic domain of TS. Additionally, we evaluated the effect of the presence or absence of the signal peptide on the immunization with plasmid DNA. For this purpose, three plasmids were generated containing the coding region for the catalytic domain of TS. The TS gene was inserted into

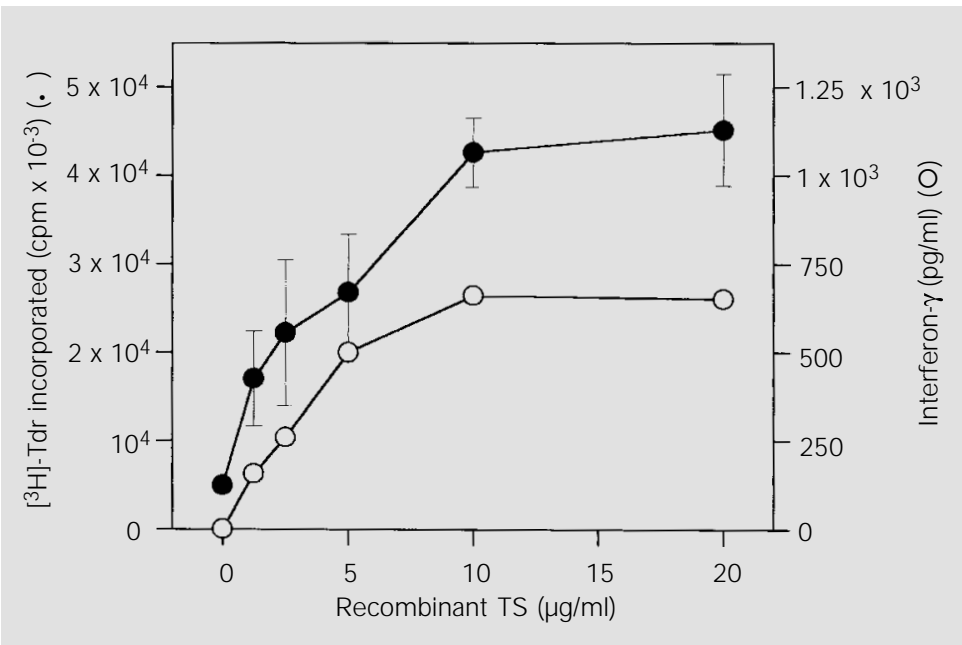

Figure 3 - Proliferative response and interferon- $\gamma$ production by peripheral blood mononuclear cells of a chagasic patient upon stimulation with recombinant transsialidase (TS).

Table 1 - Antibody induction by immunization with TS plasmids.

${ }^{1}$ Based on the sequence of gene TS 154 cloned from T. cruzi Y strain (17). Length is reported in terms of number of amino acid residues (aa).

\begin{tabular}{lccccc}
\hline Plasmid & Vector & Translated amino acids & Length (aa) & Antibody titers & Inhibition of TS activity \\
\hline B43 & pcDNA3 & $33-678$ & 645 & $1.63 \times 10^{4}$ & $72 \pm 21$ \\
154/13 & pCDNA3 & $1-678$ & 678 & $1.69 \times 10^{4}$ & $86 \pm 13$ \\
Cl-44 & VR1012 & $1-678$ & 678 & $1.68 \times 10^{4}$ & $64 \pm 27$ \\
pCDNA3 & pCDNA3 & - & - & $<1: 100$ & $11 \pm 7$ \\
VR1012 & VR1012 & - & - & $<1: 100$ & $1.3 \pm 3.3$
\end{tabular}


Table 2 - Survival of $B A L B / C$ and A/Sn mice after challenge with $T$. cruzi trypomastigotes.

Mice were immunized with 4 doses of the indicated plasmid. Each dose consisted of $100 \mu \mathrm{g}$ of DNA per animal. BALB/C and A/Sn mice were challenged with 6,500 and 250 T. cruzi trypomastigotes, respectively.

\begin{tabular}{lcccc}
\hline Mouse strain & Plasmid & $\begin{array}{c}\text { Number of } \\
\text { experiments }\end{array}$ & $\begin{array}{c}\text { Number of mice } \\
\text { (protected/challenged) }\end{array}$ & Protection (\%) \\
\hline BALB/C & PCDNA3 & 3 & $2 / 20$ & $10 \%$ \\
BALB/C & $154 / 13$ & 3 & $20 / 23$ & $87 \%$ \\
A/Sn & PCDNA3 & 3 & $0 / 15$ & $0 \%$ \\
A/Sn & $154 / 13$ & 3 & $0 / 15$ & $0 \%$ \\
A/Sn & VR1012 & 2 & $0 / 10$ & $0 \%$ \\
A/Sn & Cl-44 & 2 & $0 / 8$ & $0 \%$
\end{tabular}

the pcDNA3 vector with or without the coding region for the TS signal peptide. These plasmids were found to be equally immunogenic by inducing antibodies to TS as estimated by ELISA or inhibition of TS enzymatic activity (Table 1 and Ref. 23).

Subsequently, we used one of these plasmids to determine whether the TS gene could elicit $\mathrm{T}$ cell-mediated and protective immunity against $T$. cruzi infection in mice. BALB/ c mice immunized with plasmid $154 / 13$ containing the gene encoding the catalytic domain of trans-sialidase generated specific immune responses, as measured by antibody production and $\mathrm{T}$ cell activation (24). Although the major immunoglobulin $\mathrm{G}$ produced in response to the TS gene was IgG1, we noticed that $T$ cells preferentially produced interferon- $\gamma$. To understand this apparent contradiction, we derived $T$ cell clones from DNA-immunized mice. We found that $\mathrm{CD}^{+} \mathrm{T}$ cell clones produced high levels of interferon- $\gamma$ but failed to secrete IL- 4 or IL10 (TH1 cells). In addition, we isolated CD4 ${ }^{+}$ T cell clones that secreted IL-4 and IL- 10 but failed to produce interferon- $\gamma$ (TH2 cells, Rodrigues MM, Ribeirão M, PereiraChiccola VL, Renia L, Schenkman S and Costa F, unpublished results). Our results demonstrate that $\mathrm{TH} 1$ and $\mathrm{TH} 2 \mathrm{CD}^{+}$cells coexist in mice immunized with the TS gene.

In addition to interferon- $\gamma$-producing
$\mathrm{CD}^{+} \mathrm{T}$ cells, we demonstrated that $35 \%$ of the interferon- $\gamma$ secreted came from $\mathrm{CD}^{+} \mathrm{T}$ cells. To confirm the existence of this T cell subtype, we also generated $\mathrm{T}$ cell clones using as target cells A20J cells transfected with the TS gene. These clones produce large amounts of interferon- $\gamma$ upon stimulation with TS-transfected syngeneic cells. Considering that interferon- $\gamma$ has been implicated in resistance against $T$. cruzi infection (25), it is quite possible that both cell types mediated protective immunity in our model. In support of this hypothesis, we observed that upon challenge with blood stages of T. cruzi, BALB/c mice showed a significant reduction in the peak of parasitemia (24). Most relevant, $87 \%$ of these animals survived the acute infection induced by blood stages of $T$. cruzi. In contrast, there was only $10 \%$ survival in control mice immunized with the vector alone (Table 2). The protective immunity observed in BALB/c mice was strain specific since $\mathrm{A} / \mathrm{Sn}$ mice immunized with this same plasmid failed to survive the infection.

\section{Conclusions}

The molecular characterization of T. cruzi TS opened the possibility of designing experiments to study naturally acquired human immunity and to compare it with immunity elicited by vaccination in the experimental models. Our data strongly suggest that immunity to TS is deleterious to the parasite, protecting the host. In the experimental model, a similar immunity pattern can be obtained by immunization with a naked DNA vaccine, inducing the production of inhibitory antibodies, as well as the activation of interferon- $\gamma$-producing T cells. Although this is clearly a protective response, protective immunity depends on the genetic background of the host. Future studies may reveal whether immunity to TS also contributes to the pathology of chronic Chagas' disease in humans. 


\section{References}

1. de Andrade AL, Zicker F, de Oliveira RM, Almeida Silva S, Luquetti A, Travassos LR, Almeida IC, de Andrade SS, de Andrade JG \& Martelli CM (1996). Randomised trial of efficacy of benznidazole in treatment of early Trypanosoma cruzi infection. Lancet, 348: 1407-1413.

2. Viotti R, Vigliano $C$, Armenti $H \&$ Segura $E$ (1994). Treatment of chronic Chagas' disease with benznidazole: clinical and serologic evolution of patients with long-term follow up. American Heart J ournal, 127: 151-162.

3. Cazzulo JJ \& Frasch ACC (1992). SAPA/ trans-sialidase and cruzipain: two antigens from Trypanosoma cruzi contain immunodominant but enzymatically inactive domains. FASEB J ournal, 6: 3259-3264.

4. Cross GAM \& Tackle GB (1993). The surface trans-sialidase family of Trypanosoma cruzi. Annual Review of Microbiology, 46: 383-411.

5. Schenkman S, Eichinger D, Pereira MEA \& Nussenzweig $\vee$ (1994). Structural and functional properties of Trypanosoma trans-sialidase. Annual Review of Microbiology, 48: 499-523.

6. Ouassi MA, CornetteJ \& Capron A (1986). Identification and isolation of Trypanosoma cruzi trypomastigote cell surface protein with properties expected of a fibronectin receptor. Molecular and Biochemical Parasitology, 19: 201-211.

7. Lima MF \& Villalta F (1989). Trypanosoma cruzi trypomastigote clones differentially express a parasite cell adhesion molecule. Molecular and Biochemical Parasitology, 33: 159-170.

8. Giordano R, Chammas R, Veiga SS, Colli W \& Alves MJ (1994). An acidic component of the heterogeneous Tc- 85 protein family from the surface of Trypanosoma cruzi is a laminin binding glycoprotein. Molecular and Biochemical Parasitology, 65: 85-94.

9. Ming $M$, Chuenkova $M$, Ortega-Barria $M$ \& Pereira MEA (1993). Mediation of Trypanosoma cruzi invasion by sialic acid on the host cell and trans-sialidase on the trypanosome. Molecular and Biochemical Parasitology, 59: 234-252.

10. Kahn S, Wleklinski M, Aruffo A, Farr A,
Coder D \& Khan M (1995). Trypanosoma cruzi amastigote adhesion to macrophages is facilitated by the mannose receptor. J ournal of Experimental Medicine, 182: 1243-1258.

11. Pereira MEA, Zhang K, Gong Y, Herrera EM \& Ming M (1996). Invasive phenotype of Trypanosoma cruzi is restricted to a population expressing trans-sialidase. Infection and Immunity, 64: 3884-3892.

12. Schenkman S, Man-Shiow J, Hart GW \& Nussenzweig $\vee$ (1991). A novel cell surface trans-sialidase of Trypanosoma cruzi generates a stage-specific epitope required for invasion of mammalian cells. Cell, 65: 1117-1125.

13. Schenkman S, De Carvalho LP \& Nussenzweig V (1992). Trypanosoma cruzi trans-sialidase and neuraminidase activities can be mediated by the same enzymes. J oumal of Experimental Medicine, 175: 567-575.

14. Schenkman RPF, Vandekerckhove $F$ \& Schenkman S (1993). Mammalian cell sialic acid enhances Trypanosoma cruzi invasion. Infection and Immunity, 61: 898902.

15. Pereira MEA, Meija J S, Ortega-Barria E, Matzilevich D \& Prioli RP (1991). Trypanosoma cruzi neuraminidase contains sequences similar to bacterial neuraminidases, YWTD repeats of the low density receptor, and type III module of fibronectin. J ournal of Experimental Medicine, 174: 179-191.

16. Parodi A, Pollevick GD, Mautner M, Buschiazzo A, Sanchez DO \& Frasch ACC (1992). Identification of the gene(s) encoding the trans-sialidase of Trypanosoma cruzi. EMBO J ournal, 11: 1705-1710.

17. Uemura $H$, Schenkman $S$, Nussenzweig $V$ \& Eichinger D (1992). Only some members of a gene family in Trypanosoma cruzi encode proteins that express both trans-sialidase and neuraminidase activities. EMBO J ournal, 11: 3837-3844.

18. Ribeirão $M$, Pereira-Chioccola VL, Eichinger D, Rodrigues MM \& Schenkman S (1997). Temperature differences for trans-glycosylation and hydrolysis reaction reveal an acceptor binding site in the catalytic mechanism of Trypa- nosoma cruzi trans-sialidase. Glycobiology, 7: 1237-1246.

19. Pereira-Chioccola VL, Schenkman $\mathrm{S} \&$ Kloetzel J K (1994). Sera from chronic chagasic patients and rodents infected with Trypanosoma cruzi inhibit transsialidase by recognizing its amino-terminal and catalytic domain. Infection and Immunity, 62: 2973-2978.

20. Leguizamon MS, Campetella O, Russomando G, Almiron M, GonzalezCappa SM \& Frasch AC (1994). Antibodies inhibiting Trypanosoma cruzi transsialidase activity in sera from human infections. J ournal of Infectious Disease, 170: 1570-1574.

21. Chuenkova M \& Pereira MEA (1995). Trypanosoma cruzi trans-sialidase: Enhancement of virulence in a murine model of Chagas' disease. J oumal of Experimental Medicine, 181: 1693-1703.

22. Franchin G, Pereira-Chioccola VL, Schenkman S \& Rodrigues MM (1997). Passive transfer of a monoclonal antibody specific for a sialic acid-dependent epitope on the surface of Trypanosoma cruzi trypomastigotes reduces infection in mice. Infection and Immunity, 65: 25482554.

23. Pereira-Chioccola VL, Costa $F$, Ribeirão $M$, Soares IS, Arena F, Schenkman $S \&$ Rodrigues MM (1998). Comparison of antibody and protective immune responses against Trypanosoma cruzi infection elicited by immunization with a parasite antigen delivered as naked DNA or recombinant protein. Parasite Immunology, 20: (in press).

24. Costa F, Franchin G, Pereira-Chioccola VL, Ribeirão $M$, Schenkman $S \&$ Rodrigues MM (1998). Immunization with a plasmid DNA containing the gene of transsialidase reduces Trypanosoma cruzi infection in mice. Vaccine, 16: 768-774.

25. Hölscher C, Kölher G, Müller U, Mossman H, Schaub GA \& Brombacher F (1998). Defective nitric oxide effector function leads to extreme susceptibility of Trypanosoma cruzi-infected mice deficient in gamma interferon receptor or inducible nitric oxide synthase. Infection and Immunity, 66: 1208-1215. 